\title{
Introduction to the proceedings of the 9th International Symbiosis Congress
}

\author{
David H. S. Richardson ${ }^{1} \cdot$ Simon K. Davy ${ }^{2} \cdot$ Marc-André Selosse $^{3}$
}

Received: 10 January 2019 / Accepted: 7 February 2019 / Published online: 8 March 2019

(C) Springer Nature B.V. 2019

This special issue of Symbiosis contains a selection of papers that were presented during the 9th International Symbiosis Society Congress (ISS), which was held at the Hill Alumni Center at Oregon State University (OSU), USA from the 15th to the 20th July, 2018. The two adjacent buildings provided space for concurrent sessions and poster presentations. Many participants flew into Portland and then took the hour and a half shuttle to Corvallis giving them a glimpse of the countryside. This was further appreciated by the mid-congress field trips, one to the spectacular rocky coast to view tide pool organisms (Fig. 1) and the other to Marys Peak, with huge coniferous trees and a rich assortment of lichens, mosses and fungi on the slopes. The subalpine area on the top, where a picnic lunch was taken, had magnificent views of distant mountains (Fig. 2). The 209 Congress participants came from some 20 countries with 138 being from the USA, 16 from Canada, eight from Saudi Arabia and France, six from Germany and four each from Australia, New Zealand and Mexico. There were participants from 29 different US states.

The highlight of the daily programme was provided by a presentation by one or more of the eight plenary speakers. In order of presentation, they were Peter Kennedy - University of Minnesota 'Inter-guild fungal interactions and carbon cycling in forest soils', Toby Spribille - University of Alberta 'Lichen symbiosis, the emergence of architecture', Rebecca Vega-Thurber - Oregon State University 'The global coral microbiome project', Elizabeth Arnold

David H. S. Richardson

david.richardson@smu.ca

Saint Mary's University, Halifax, Nova Scotia, Canada

2 Victoria University of Wellington, Kelburn, Wellington 6012, New Zealand

3 Muséum national d'Histoire naturelle, Paris 75005, France

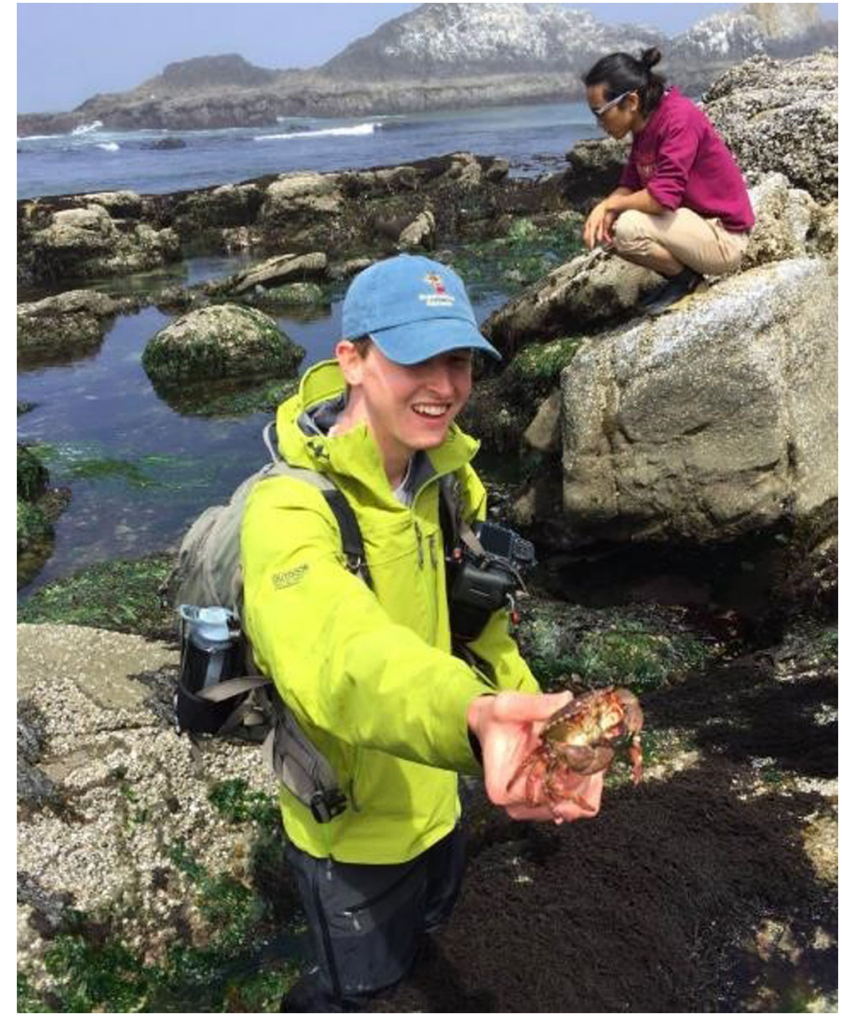

Fig. 1 The seashore field trip as a part of the ISS Congress to examine rock pools on the pacific coast near Corvallis, Oregon

- University of Arizona 'Mosaics, megabases and Matryoshki: a leaf to landscape perspective on the symbiotic renaissance', Margaret McFall-Ngai - University of Hawaii 'Waging peace: diplomatic relations in animal-bacterial symbioses', Seth Bordenstein Vanderbilt University 'The genetic legacy of bacteriophage in animal reproduction', Joel Sachs - University of California at Riverside 'Cheating and punishment in plant-bacterial symbioses', Gary Stacey - University of 
Fig. 2 The field trip to Marys Peak Oregon which, at $4097 \mathrm{ft}$, is the highest point in Oregon's Coast Range and where the ISS Congress participants had a picnic lunch. From the peak on a clear day the Cascade mountain peaks and the Pacific Ocean can be seen

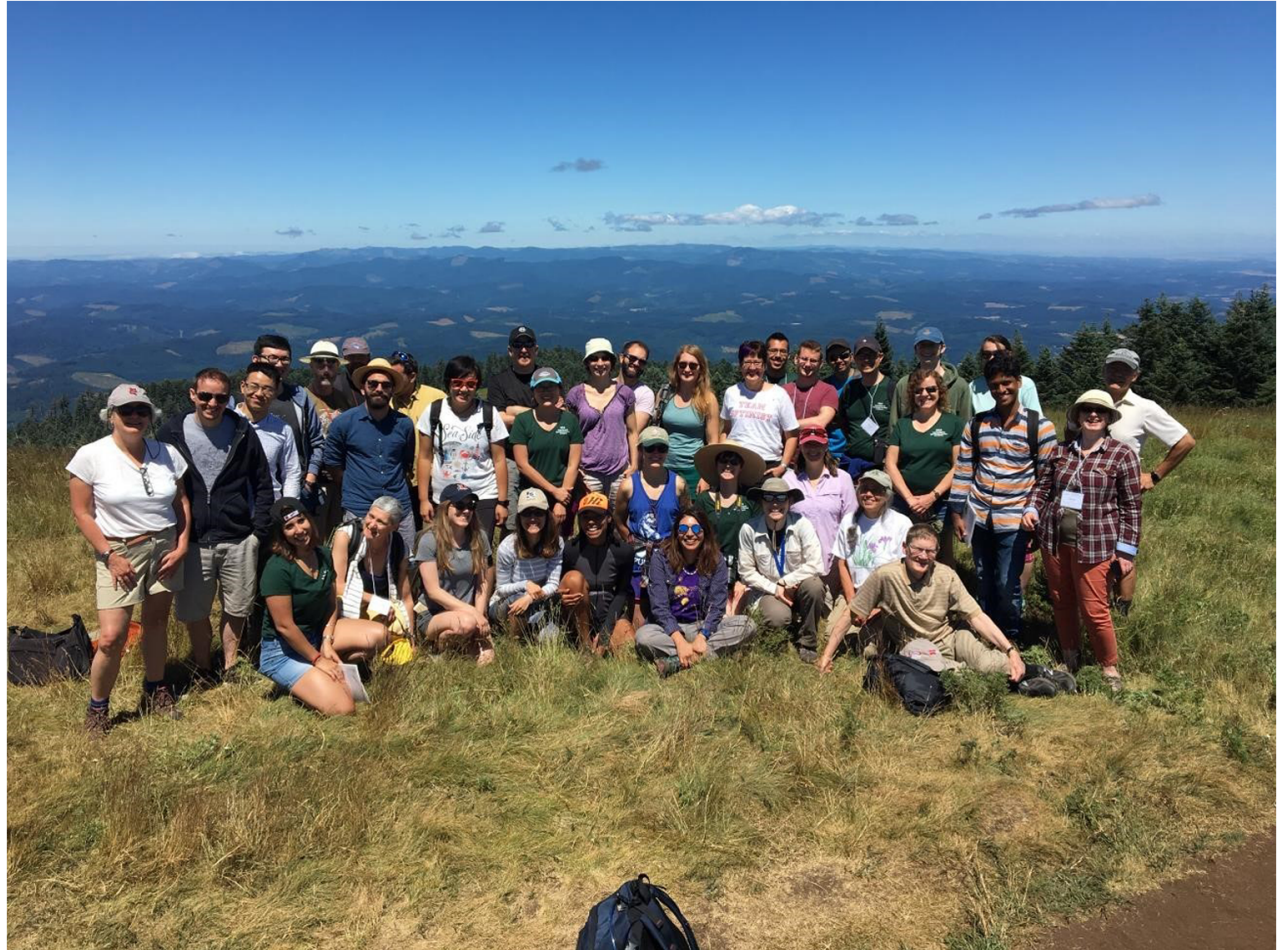

Missouri Columbia 'Can we transfer biological nitrogen fixation to non-leguminous plants?'. In addition there was an evening keynote address by Ed Yong - science journalist and writer 'Telling stories about microbes and the people who study them'.

The congress was organized into thematic sessions like 'Ecology of symbiosis' and focused sessions on, for example, 'Symbiodinium', 'lichens', 'bacterial-coral interactions', 'virus interactions', 'Mycorrhizae', ‘protists and Cnidarians', etc. In addition to the daily talks, there were early evening poster sessions with a total of 65 posters that, with the available excellent light refreshments, provided lively discussion between the congress participants. Another highlight of the 9th ISS Congress was the banquet, which was held outside in an orchard, at Cornelius Farm (Fig. 3). Lively entertainment was provided by a local Ska band (a mix of rock and reggae) called Ludicrous Speed.

As in previous congresses there was a Symbiosis Education Session. This has been a tradition since the second Congress in Cape Cod in 1996. It was introduced by Douglas Zook who, in the no-longer published 'Symbiosis newsletter' (vol. 1, issue 1, page 3), reported that "five "stations" or learning centers were established in the room, partly as an attempt to directly model innovative pedagogy by truly involving participants at learning and doing rather than only by a listening and lecturing process (...) It was fluid and fertile in a stimulating setting.' This year's session, organized by MarcAndré Selosse, Sharon L. Doty and Patricia Stock, incorporated no less than 21 displays! (Table 1). Each leader displayed his/her research model and suggested ways of teaching about the particular symbiosis. The Education session always attracts a good audience made up of teachers looking for tricks and material to teach (Fig. 4). A lot of colleagues also attended, simply being curious about the research models that others use. All were intrigued by the great diversity of the displays, experimental approaches and observations (Fig. 5). OSU students helped by providing microscopes, screens, computers and equipment in the two rooms set aside and devoted to the displays of symbiosis teaching material (Fig. 6). The success of the session means that it will remain a hallmark of ISS congresses. We thank all the contributors and look forward to the session at the 10th ISS Congress in Lyon, France. 
Fig. 3 The ISS Congress Dinner held at Cornelius Farm and the entertainment was provided by a Ska band (a mix of rock and reggae)

Table 1 Displays at the Education session of 9th ISS Congress

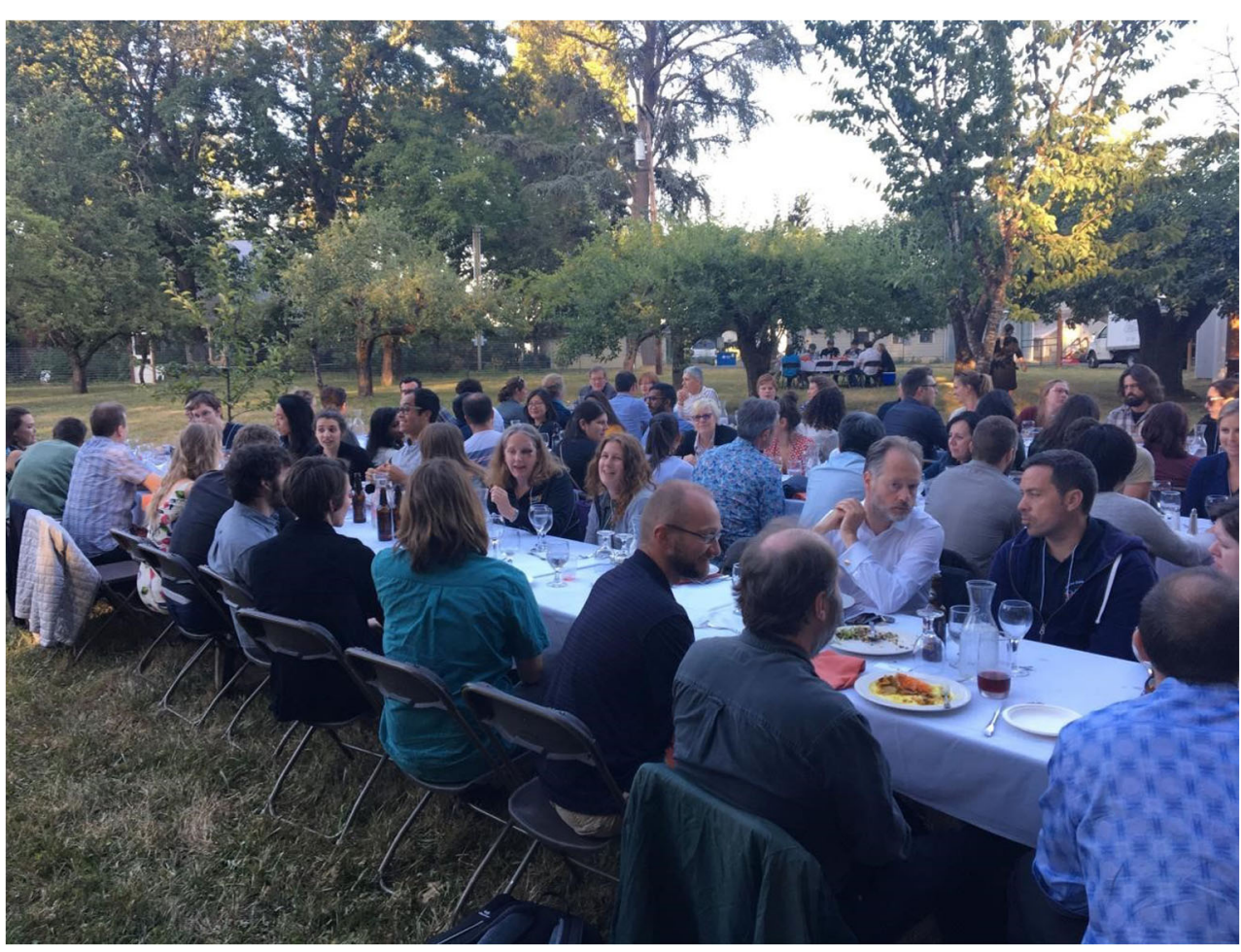

Displayer

1. Patricia Stock

2. Marc-André Selosse

3. Ryan Kerney

4. Pol Nadal-Jimenez

5. Manju M. Gupta \&

Mahaveer P. Sharma

6. Eric Vukicevich

7. Sharon L. Doty

8. Tsubasa Ohbayashi

9. Jack Cushman Koch

10. Bérénice Piquet

11. Nikolaus Leisch

12. Erika Diaz

13. Camille Wendlandt

14. Klara Scharnagl

15. Melissa McCormick

16. Ulrike Ruprecht

17. Justin Maire

18. David Hembry

19. Amber McCammon \& Paul C. Sikkel

20. Fabrice Not

21. David Richardson
Title

Nematode-bacteria symbiosis

The overlooked tree-mites symbiosis

The Ambystoma - algae symbiosis

Nasonia vitripennis and superparasitism

Arbuscular mycrorhizal symbiosis

The dynamics of the AM fungal symbiosis in aging roots

Plant microbiome (bacterial endophytes)

The bean bug Riptortus pedestris and its midgut

Photosynthetic symbioses between algae and anemones or corals

Bathymodiolus azoricus and their endosymbionts

Exploring the oases of the deep-sea

From farm to symbiont using the squash bug system

Phenotypic variation in legumes

Lichens

Orchid mycorrhizal fungi and endobacteria, a symbiosis within a symbiosis

Lichens - tough organism in extreme habitats

The cereal weevil and its nutritional endosymbiont

Leaf flower-moth interactions, a kind of brood pollination

Introducing symbiosis via an ecological model in an informal learning exhibit

PlanktoMania: dive into the microscopic world of the oceans through augmented and virtual reality

Lichens (collected on the Marys Peak Field Trip) 
Fig. 4 The Education session at the ISS Congress where lively discussions took place over the various presentations

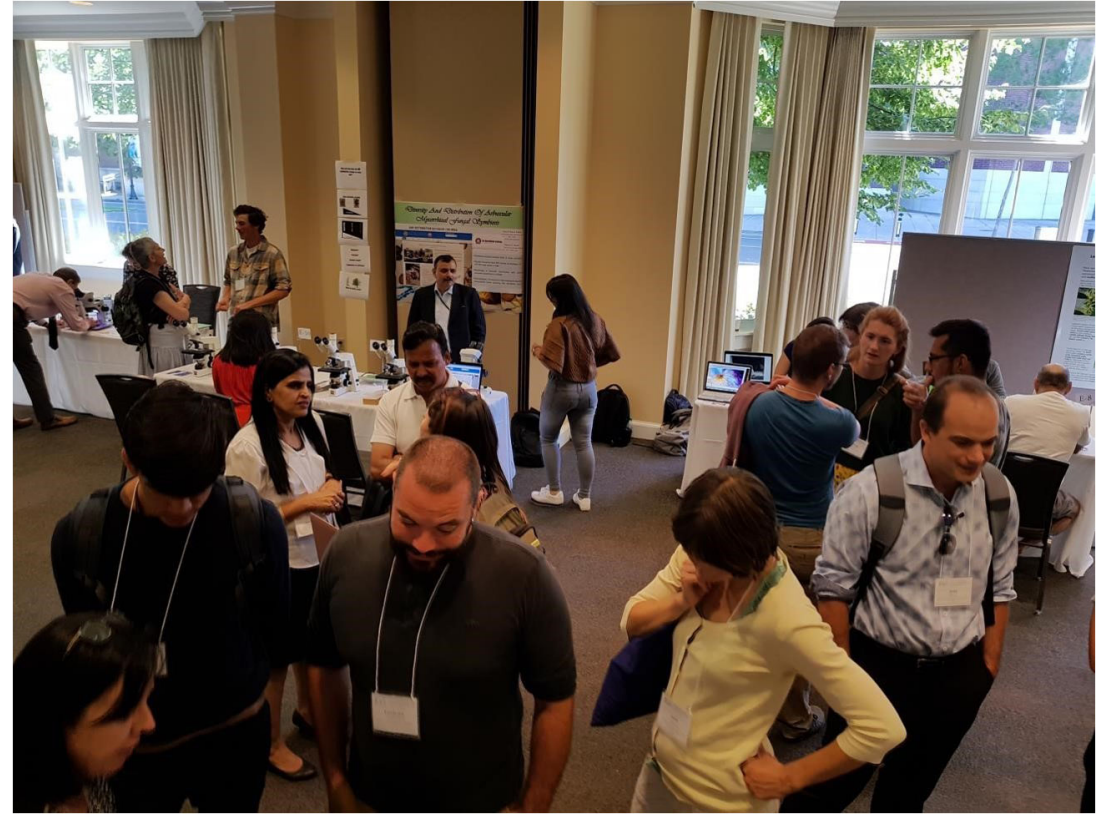

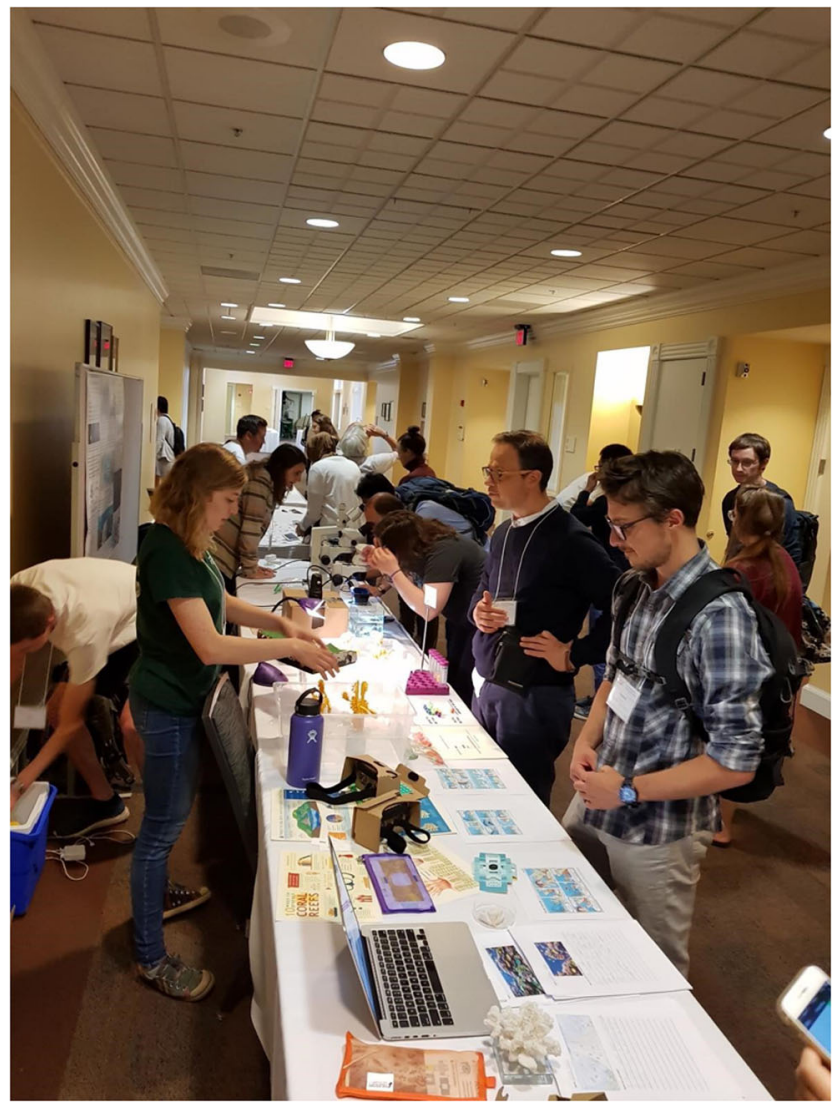

Fig. 5 Active demonstrations of the various symbiotic systems in one of the two demonstration areas
One of the defining features of this particular ISS congress was a preponderance of talks on cnidariandinoflagellate symbiosis, which arose due to an associated two-day workshop on the 'Aiptasia' (Exaiptasia pallida) model system held directly after the main meeting. This workshop was supported by NSF funding to Virginia Weis (OSU), Arthur Grossman (Carnegie Institute), John Pringle (Stanford University), and Matt DeGennaro and Mauricio Rodriguez-Lanetty (both Florida-International University), and involved over 50 invitees from around the world. These invitees included academics and research students from both traditional universities and liberal arts colleges, highlighting the twin goals of identifying research priorities and opportunities, and the application of the Aiptasia model system to undergraduate teaching. The workshop was both hugely stimulating and productive, resulting in improved integration and communication across the rapidly expanding Aiptasia field, and clear goals for future research and teaching ventures. The ISS Congress provides an ideal opportunity for satellite meetings and we strongly encourage others to organize similar events in the future.

We trust that you find the proceedings of the 9th ISS Congress as interesting and enjoyable as we who attended the Congress did when attending the lectures and poster sessions. We thank the organizing committee for their 
Fig. 6 The lichen area: Who can name the difference between the various genera?

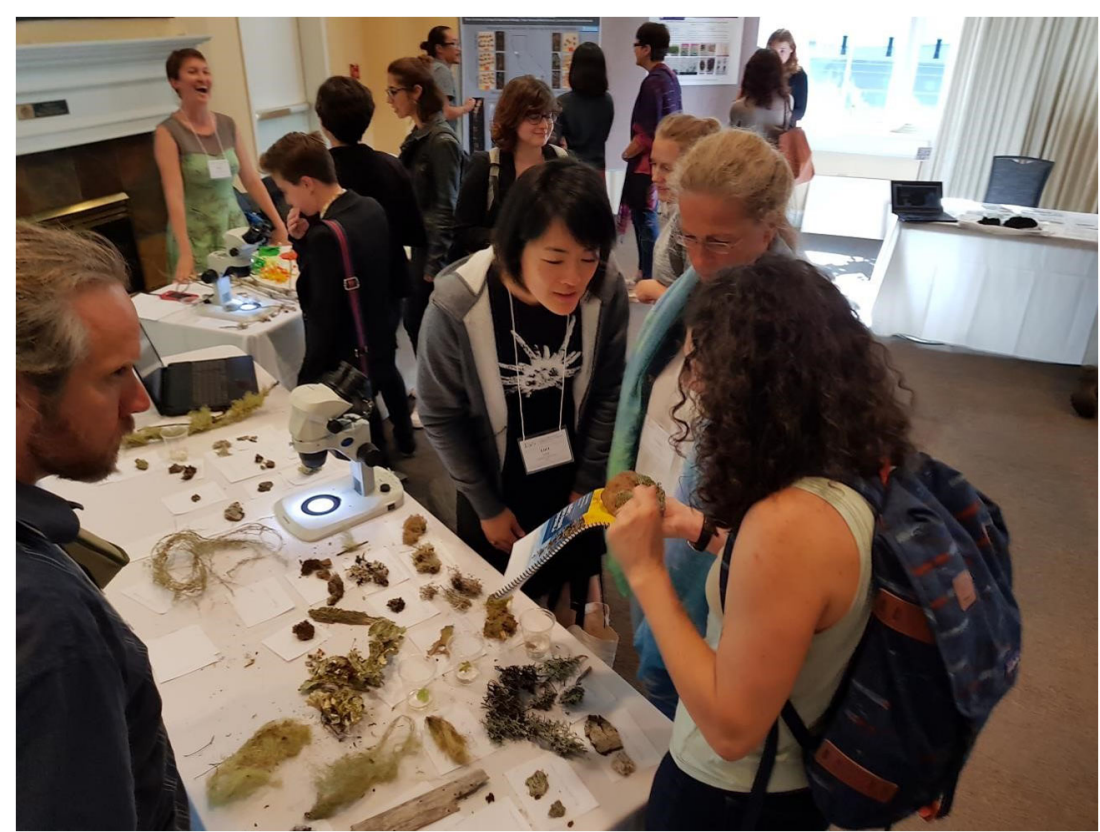

splendid work, led by Virginia Weis of OSU, who was ably supported by Toby Spribille, Amanda Brown, Thomas Sharpton and Sharon Doty, as well at the students including 10 undergraduate and a group of graduate students who served as volunteers at the registration desk. They offered their assistance and gave up many hours of their time to ensure that the conference ran so smoothly with the help of the others at the OSU conference centre. Together, they organized a truly outstanding congress that was intellectually stimulating, provided excellent meals and concluded with a memorable banquet.

Publisher's note Springer Nature remains neutral with regard to jurisdictional claims in published maps and institutional affiliations. 